\title{
Arte naquele tempo (Memórias)
}

\author{
Antonio Candido
}

\section{Resumo}

Despertado por recortes de memória, este depoimento de Antonio Candido traz à tona o ambiente de renovação das artes que sucedeu na cidade de São Paulo - por ocasião da segunda metade dos anos 1930 e nas décadas seguintes. Ao relembrar importantes exposições ocorridas na capital, o relato evoca os nomes atuantes no período e a vida social que animava aquele grupo de artistas e intelectuais. A evocação pessoal, neste caso, coincide com um momento de virada no gosto estético da época.

\section{Palavras-chave}

Vida cultural na cidade de São Paulo, Exposições de arte, anos 1930, 1940 e 1950, renovação artística, memória.

Recebido em $1 \stackrel{0}{\circ}$ de novembro de 2011

Aprovado em 8 de dezembro de 2011

1 Professor Emérito da FFLCH-USP e doutor honoris causa pela Unicamp. Escritor e crítico literário de reconhecida atuação intelectual e política, é autor, dentre outras obras, de Formação da literatura brasileira (Ouro Sobre Azul, 20o6). 


\section{Art Back Then (Memories)}

\section{Antonio Candido}

\section{Abstract}

Triggered by jolts of memory, this account by Antonio Candido revisits the atmosphere of artistic renewal that took hold in São Paulo city in the second half of the 1930s and which extended throughout subsequent decades. Recalling important exhibitions held in the city, Candido evokes the main players of the time and the social life enjoyed by the city's artists and intellectuals. In this text, a personal glance back in time coincides with a watershed in the aesthetic taste of the day.

\section{Keywords}

Cultural life in São Paulo city, Art exhibitions, the 1930's, 40's and 50's, artistic renewal, memory. 


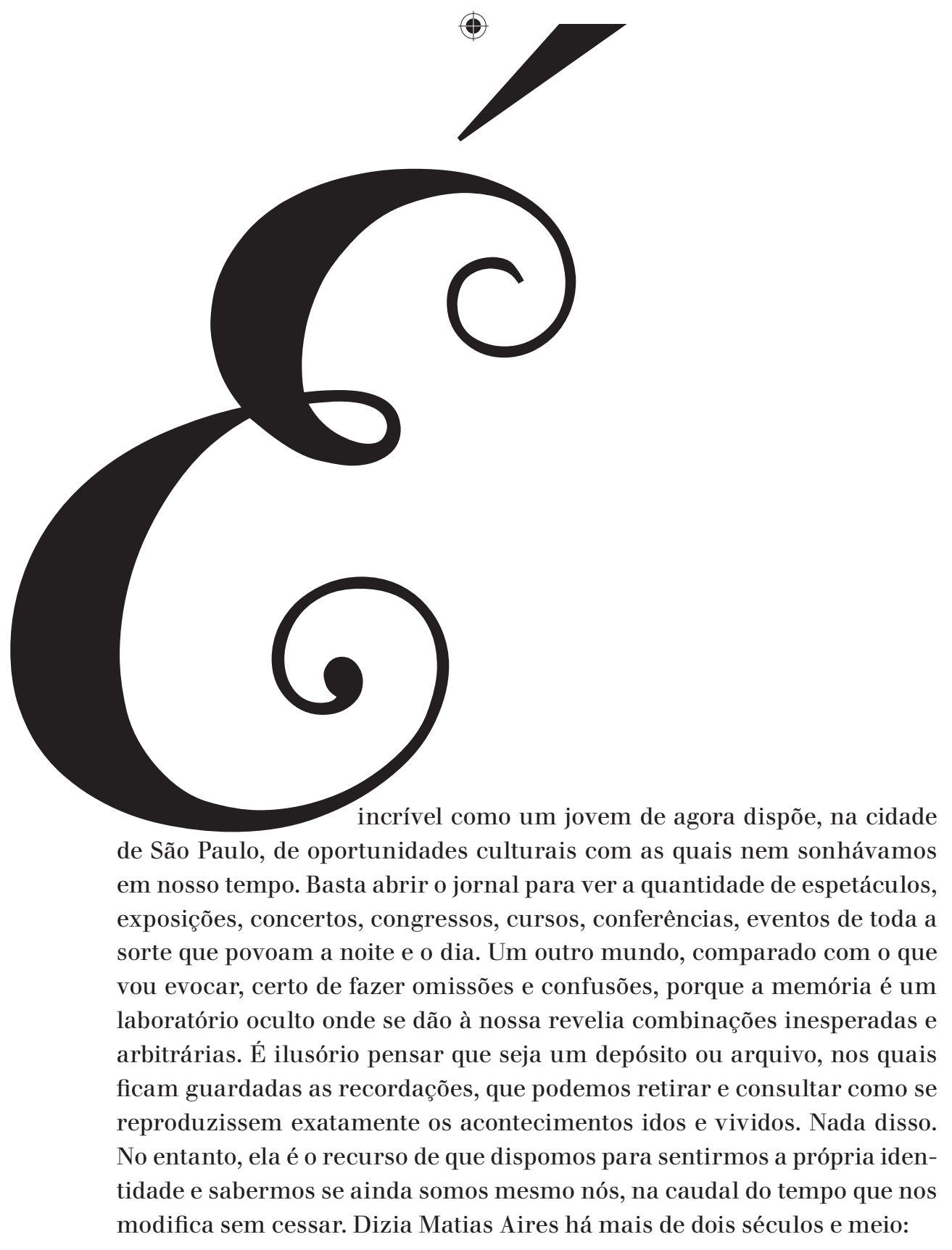

A cada passo que damos no discurso da vida, imos nascendo de novo, porque a cada passo imos deixando o que fomos, e começando a ser outros: cada dia nascemos, porque cada dia mudamos, e quanto mais nascemos desta sorte, tanto mais nos fica perto o fim que nos espera.

Lembrar talvez seja uma tentativa de manter na mão o fio que nos liga a nós mesmos na "sucessividade dos segundos" (Augusto dos Anjos).

I5

revista ieb $n_{54} 2012$ set./mar. p. 13-20 
Quando vim para São Paulo a fim de estudar, em janeiro de 1936, a cidade havia ultrapassado um milhão de habitantes, motivo de orgulho dos paulistanos. ("Vamos passar à frente do Rio!") A vida artística era insignificante, comparada ao que é hoje, e só me lembro de um museu de arte, a Pinacoteca do Estado, situada num velho prédio da Rua Onze de Agosto, posto abaixo para a construção do Palácio de Justiça. O acervo era de tipo maciçamente conservador e fui lá pelo menos uma vez. Em seguida ela mudou para o prédio do Liceu de Artes e Ofícios, onde está até hoje, e eu a frequentei bastante, porque, ao contrário da minha geração, muito presa ao espírito da então recente Semana de Arte Moderna, sempre me interessei pela pintura brasileira tradicional. Atavismo? Um de meus bisavós maternos era amador de pintura e exerceu de 1874 a 1888, ano de sua morte, o cargo de diretor da Imperial Academia de Belas Artes e da Pinacoteca do Rio de Janeiro.

As exposiçõesnão eram frequentes em São Pauloe, a julgarporaquelas das quais me lembro, em geral de pintura acadêmica secundária. Não sei se havia muitos locais para elas. Um deles era o Palacete das Arcadas, na Rua Quintino Bocaiuva, numa sala ao fundo do corredor de entrada, onde mais tarde se instalou um cartório. Ali vi mostras de pintores do tempo, mas lembro de poucas, inclusive uma interessante de Helios Seelinger e outra, ousada para a época, de Hernani de Irajá, médico sexólogo e escritor meio sensacionalista, além de pintor. Era toda composta por nus femininos muito realistas, os primeiros que vi sem a depilação de praxe desde a Antiguidade. Devia haver outros locais e outras exposições, que não cheguei a ver ou das quais me esqueci. Mas não esqueci que nas residências onde havia bons quadros predominavam os de Marques Campão, Clodomiro Amazonas, Tulio Mugnaini, Campos Aires, mestres paulistas acadêmicos que a classe média apreciava. O mais fino, no entanto, era comprar quadros acadêmicos secundários franceses e italianos, de preferência premiados em exposições europeias (como atestavam as plaquinhas na moldura), o que podia ser feito na Galeria Rembrant, na esquina da Rua Barão de Itapetininga com a Dom José de Barros.

Posso dizer que a emoção inicial que tive com a pintura em São Paulo foi o Primeiro Salão de Maio, de 1937, realizado numa grande sala térrea do Hotel Esplanada, atrás do teatro Municipal, mais tarde sede de uma empresa. Era um mundo novo que vinha quebrar a minha rotina, baseada no gesto ortodoxo de meus pais e na experiência precoce em museus europeus.

Estive um ano na Europa com minha família do fim de 1928 ao fim de 1929 e nós os visitávamos frequentemente. Como passamos a maior parte do tempo em Paris, era principalmente o do Louvre, perto do qual 
morávamos. Íamos também ao Luxemburgo, que depois deixou de ser museu e naquele tempo abrigava os impressionistas, depois transferidos para o Jeu de Paume, embora no Louvre houvesse um ou outro quadro deles, como a Olímpia, de Manet, que vi meio espantado e contrastava de maneira gritante com um dos meus prediletos, A fonte, de Ingres. Este legitimava a contemplação do nu feminino graças ao toque de frialdade casta, enquanto Olímpia era agressivo, e por isso não podia decerto ser olhado por um menino com a mesma aprovação dos pais. Essa experiência europeia foi a base remota da minha iniciação na pintura, continuada aqui nos álbuns e catálogos que trouxemos e eu vivia folheando.

O Salão de Maio foi portanto o choque antitético, a iniciação na arte contemporânea. Havia quadros e esculturas de muitos artistas, alguns bem convencionais, mas o que me fascinou foram sobretudo as obras de dois pintores diferentes e mesmo opostos. De um lado, certa tela de Flávio de Carvalho, representando se bem me lembro uma mulher deitada, cada parte do corpo de cor diferente, em pinceladas sumárias e violentas que pareciam quebrar a continuidade da composição. De outro lado, dois quadros realistas de Carlos Prado, de tema popular, feitos em tons escuros, com belos castanhos e azuis.

Nesse Salão fui testemunha de um fato curioso. Bem na entrada havia a estatueta em argila de uma mulher nua, que, quando saí, não tinha mais a cabeça. Ao lado, falava exaltado com os guardas um homenzinho que só mais tarde identifiquei: era Quirino da Silva, mais conhecido como pintor, indignado porque alguém, durante minha visita, tinha cortado a cabeça da escultura com uma bengalada de protesto moralista e conservador...

O Primeiro Salão de Maio revirou minha sensibilidade, o que foi logo reforçado pela leitura do livro de um futurista italiano, o pintor Gino Severini: Ragionamenti sulle artifigurative. Eu estava fazendo dezenove anos e só então ia entrar na modernidade das artes, superando, mas não anulando a formação precoce de menino que tinha passado na Europa uma temporada cheia de museus, guiado pelos pais segundo o respeito quase religioso pela arte que havia em alguns setores da classe média instruída daquele tempo.

Neste sentido, menciono que em setembro de 1929, indo de Berlim a Karlsbad, na então Checoslováquia, onde meu pai participaria de um congresso médico, paramos um dia em Dresden por vontade dele para ver a Madonna Sistina, de Rafael. O quadro ficava numa pequena sala forrada por cortinas pretas de veludo, contra as quais se destacava como objeto de culto, contemplado em silêncio respeitoso. Muito mais tarde, já homem maduro, bem depois da morte de meu pai, entendi o porquê 
dessa visita: a Madonna Sistina era o quadro querido de seu autor predileto, Dostoievski, que tinha no escritório uma reprodução dele.

A partir de 1940 a experiência reveladora do Salão de Maio se prolongou de certo modo pelas visitas à casa de Oswald de Andrade, onde havia obras de Picasso, Léger, Braque, De Chirico, além de brasileiros, como Tarsila do Amaral e Flávio de Carvalho.

Outro ano importante foi 1941. Nele houve a Exposição de Pintura Francesa na Galeria Itá, Rua Barão de Itapetininga, acontecimento extraordinário que nos pôs em contato com a pintura de Ingres aos nossos dias. Ela ficou aberta muito tempo, acho que encalhada por causa da guerra, tornando-se ponto de encontro, lugar de conversa e troca de impressões. Para mim foi um verdadeiro curso informal, um fator de progresso, porque eu estava vendo de novo, com olhos amadurecidos, um retalho que vira alguns anos antes em Paris com olhar inocente. E tinha muito mais orientação por parte de entendidos, como os meus professores franceses da Faculdade de Filosofia, Giuseppe Ungaretti e amigos competentes, sobretudo Lourival Gomes Machado.

Naquele ano esteve aqui o surrealista português Antonio Pedro, que ficou nosso amigo e preconizava o Dimensionismo, uma espécie de arte total feita pela convergência de todas elas. Além de escritor, era pintor inventivo e arrojado. Nós tínhamos fundado a revista Clima e patrocinamos a sua exposição, com catálogo prefaciado por Giuseppe Ungaretti.

Clima (1941-1944) dava muita atenção à pintura graças ao encarregado da seção de arte, o citado Lourival, crítico de muita acuidade, que depois teve papel importante nas Bienais e dirigiu com espírito renovador a Faculdade de Arquitetura e Urbanismo da Universidade de São Paulo. Por isso fiquei conhecendo pintores moços cujas obras eram reproduzidas na revista desde o primeiro número. Depois da exposição de Antonio Pedro patrocinamos outra, de um jovem pintor muito versátil, o suíço Jean-Pierre Chabloz, casado com brasileira, que depois se fixou no Brasil e teve atividade educacional no setor das artes. A partir de certa altura a revista passou a publicar xilogravuras, não isoladas, mas em sequência e devidas a um só artista, como se fosse colaboração dele. Publicamos assim: Lívio Abramo, Manoel Martins, Osvaldo Goeldi, Cláudio Abramo, Walter Levy.

Naquela altura a vida cultural e artística de São Paulo já era mais intensa do que o momento da minha chegada, ou pelo menos eu estava melhor informado a seu respeito. Havia eventos, concertos, conferências, mostras da produção local recente. Lembro, por exemplo, a Casa e Jardim, na Rua Barão de Itapetininga, que vendia objetos, quadros, móveis, mas também realizava conferências e exposições numa sobreloja. Durante certo tempo esteve exposto nela, à venda, um quadro muito 
bonito de Vlaminck, paisagem de neve que eu namorava e tinha vontade de comprar. O preço não era muito alto, mas, para mim, inacessível.

Certo dia, visitando uma exposição não me lembro de quem, encontrei lá Mário de Andrade e fiquei surpreso com a observação dele, que me parecia negar o que eu supunha ser um dos seus dogmas: o nacionalismo artístico. Eu disse que certo quadro me parecia bom porque "era bem brasileiro", e ele replicou que pensar assim podia levar à valorização do pitoresco, como se fosse algo exótico para nós mesmos, quando o importante era a fatura.

Por falar em Mário, registro que a dele foi a maior coleção particular de arte que vi em São Paulo. Sem contar as esculturas, gravuras, desenhos, ela compreendia dezenas de quadros, quase todos de artistas daqui, salvo exceções, como certo guache onde se via um arlequim, atribuído a Picasso, e um painel de Lhote, Football, cujo par, Rugby, estava no Museu de Arte Moderna, de Nova York. Representados frequentemente por diversas obras cada um, enchiam as paredes Portinari, Di Cavalcanti, Guignard, Anita, Tarsila, Pancetti, Gomide, Cícero Dias, Ismael Nery, Vittorio Gobbis, Rebolo, Clovis Graciano e outros.

Em 1942 Alfredo Mesquita fundou na Rua Marconi a Livraria Jaraguá, que se tornou ponto de encontro de intelectuais e artistas. Clovis fazia lá uma espécie de plantão que atraía os colegas, de modo que eram frequentadores muitos dos que enumerei e outros, como Paulo Rossi Osir, grande leitor de Stendhal e Proust. Estava sempre lá, simpático e rabugento, um moldureiro deles, o italiano Tércio. Sobre Clovis cheguei a escrever um artigo, creio que em 1944, a propósito de uma de suas exposições. E certa vez fui ao ateliê de Manoel Martins, na Praça da Sé, com Jorge Amado e seu irmão James.

Nesse tempo viveu aqui Emiliano Di Cavalcanti, com quem tive boas relações. Morava no mesmo prédio que Flávio de Carvalho, na esquina da Praça da República com a Barão de Itapetininga, em cujo andar térreo havia o café Nosso Engenho. Di Cavalcanti fez em 1941 ou 1942, na Casa e Jardim, uma palestra interessante sobre a sua vida em Paris. Em 1947 foi ao II Congresso Brasileiro de Escritores, em Belo Horizonte, como correspondente do jornal $O$ Estado de S.Paulo, para o qual executou, a fim de ilustrar as notícias, desenhos retratando os congressistas. $\mathrm{O}$ que fez de mim era muito bom, e ele disse que eu poderia buscá-lo em sua casa depois de utilizado, mas por timidez nunca fui. Certa vez, sabendo que eu admirava muito os seus quadros, mandou dizer que poderia comprar um deles, pagando quando e como quisesse, mas perdi também essa oportunidade.

O gesto de Di Cavalcanti mostra como era difícil a vida dos pintores, que não tinham mercado para sobreviver e só podiam dispensá-lo quando 
eram ricos, como Flávio de Carvalho e Carlos Prado. Por isso acho que quase todos exerciam atividades paralelas. Rebolo, por exemplo, tinha uma empresa de pintura de paredes, e lembro que certa vez fomos conversando no mesmo ônibus até São José dos Campos, onde ele ia empreitar a de uma casa construída por Oscar Niemeyer. Clovis Graciano, do seu lado, negociava com livros raros, enquanto Bonadei desenhava figurinos e Paulo Rossi Osir tinha uma cerâmica. $\mathrm{E}$ assim por diante. Esses pintores deviam sentir-se com tão poucas perspectivas de vida material, que a admiração pela sua obra era um conforto e favorecia a generosidade. De fato, estavam dispostos a ceder por muito pouco os seus quadros a amigos que os apreciavam. Só mais tarde, creio que pelo fim dos anos 1950, surgiam marchands empreendedores, que inclusive financiavam o trabalho deles.

Nos meados do decênio de 1940 foi surgindo uma nova geração, da qual se destacou o Grupo dos 19, que contava com excelentes artistas, entre os quais Maria Leontina, Aldemir Martins, Mário Gruber Correia, Marcelo Grassman. A exposição inaugural foi num salão da Galeria Prestes Maia, que tinha se tornado espaço importante para mostras tanto de acadêmicos quanto de modernos e eu frequentei muito. Pela altura de 1946 houve nela uma exposição tocante, que marcou a volta dos contatos culturais com a França, depois da interrupção da guerra. Eram livros e obras de arte, inclusive uma série de tapeçarias de Lurçat. Quanto ao Grupo dos 19, eu me dei com Aldemir Martins e sobretudo Mário Gruber, que durante certo tempo ia pintar na garage de nossa casa, na Aclimação. Ele me deu algumas das suas gravuras iniciais e fez em 1947 um belo retrato a óleo de minha mulher. Mais tarde quis fazer o meu, mas desistiu depois de algumas sessões.

Muito interessante, sobretudo inesperado, foi o caso do jornalista Arnaldo Pedroso d'Horta, que de repente, na altura de 1950, aos trinta e cinco anos, começou a fazer desenhos, recortes, gravuras, tornando-se um artista de grande qualidade. Em $1951 \mathrm{fez} \mathrm{um} \mathrm{bom} \mathrm{retrato} \mathrm{meu} \mathrm{a} \mathrm{óleo.}$

O decênio de 1950 começou por uma experiência artística importante: a Primeira Bienal de Arte de São Paulo. Foi nela que vi quadros de pintores abstratos europeus e Lourival Gomes Machado me explicou diante deles a natureza do abstracionismo, abrindo uma província nova na minha experiência. Devo dizer que me sinto bem menos à vontade nela que do que nas anteriores, mas isso seria outra história. O decênio de 1950 viu São Paulo começar a sua perigosa carreira de megalópole, o ritmo da vida mudou, o Centro entrou a se descentralizar, os encontros pessoais que ele enquadrava foram ficando raros e tudo pareceu definir uma nova era, em cuja entrada ponho o ponto final. $\mathrm{O}$ que eu quis foi dar uma ideia do que podia ser a experiência artística de um rapaz daquele tempo, que para mim é cada vez mais, obviamente, o verdadeiro bom tempo... 